\title{
Clinical Profile of Stroke Patients Presenting to the Emergency Department of a Major Stroke Centre in Oman
}

Hasina A. Al Harthi, ${ }^{1}$ *Ammar Al Kashmiri, ${ }^{2}$ Lubna M. Zakaryia, ${ }^{2}$ Jawad A. Al-Lawati, ${ }^{3}$ Omar M. Najem, Isra Al-Lawati, ${ }^{1}$ Ghulam R. Memon, ${ }^{1}$ Amr A. Elfaham ${ }^{1}$

\begin{abstract}
Objectives: Stroke is a significant public health problem and one of the most important preventable non-communicable diseases. Preventive stroke programmes with a better focus on increasing awareness among those who are currently at risk are yet to be properly established in Oman. This study was conducted to describe the characteristics of stroke patients presenting to a tertiary care hospital in Oman. Methods: This crosssectional hospital-based study included 193 stroke cases which were prospectively recruited from the Emergency Department of Khoula Hospital, Muscat, Oman. Data were collected from November 2017 to April 2018. Results: The total number of patients was 193 with $82.9 \%$ of strokes being ischaemic strokes. Of this, $58 \%$ were male. The mean age of stroke patients was 61.05 years. Risk factors included hypertension (72.5\%) and diabetes mellitus (54.4\%). Dyslipidaemia, atrial fibrillation and ischaemic heart diseases were not particularly prevalent in the studied population and $24.4 \%$ of ischaemic strokes had large artery atherosclerosis while $21.9 \%$ had small vessel occlusion. Significantly more patients had lower Glasgow Coma Scale scores, required intensive care unit admission and experienced in-hospital deaths due to haemorrhagic stroke compared to ischaemic stroke. Conclusion: This study provides essential data regarding stroke characteristics specific to Oman's population. Most of the information obtained appears to be in-line with what has been described internationally and, hence, preventive strategies similar to those indicated in extant literature can be implemented. This information can be utilised by health administrators in planning resource allocation. Further research is needed to explore rehabilitation aspects and long-term outcomes.
\end{abstract}

Keywords: Stroke; Ischemic Stroke; Haemorrhagic Stroke; Risk Factors; Thrombolytic Therapy; Epidemiology; Oman.

\section{Advances in KNOWLEDGE}

This study provides information on the characteristics of stroke patients specific to the local population of Oman and compares them to benchmark international trends.

Information on the different risk factors associated with stroke in this population can help guide the development of specific preventive and possibly rehabilitative strategies for stroke.

\section{Application to Patient Care}

This study highlights various stroke-related aspects among patients sustaining a stroke, one of the main causes of morbidity and mortality in Oman.

Identifying the main risk factors is important in targeting the patient population at risk and providing them with the necessary means of prevention through better control of their disease.

$\mathrm{S}$ TROKE IS A PREVALENT ILLNESS WORLDWIDE WITH associated morbidity, mortality and financial costs to health systems. It is the second most common cause of death and the third most common cause of disability-adjusted life-years (DALYs) lost globally. ${ }^{1}$ Stroke is more prevalent in the Middle East compared to the Western world with an annual incidence of 180 per 100,000 individuals, with ischaemic stroke being the most common subtype. ${ }^{2}$ One study revealed that it was the leading cause of death in several middle-income Arab countries. ${ }^{3}$ Although the overall percentage of the average stroke-related DALYs lost is thought to have declined in some Arab countries, the global burden of stroke continues to rise. ${ }^{4}$ The financial costs of strokes are multitudinous due to its effects on the health system as well as the economy from loss of labour, among other costs related to the survivors and their caregivers.

Strokes constitute a significant public health problem, being one of the important preventable noncommunicable diseases. ${ }^{5}$ The majority of risk factors for stroke are modifiable; therefore, preventive strategies would be effective in reducing the incidence of new and recurrent stroke. Preventive stroke programmes with a better focus on increasing awareness among those who are currently at risk are yet to be properly 
established in many countries, including Oman. Patientsat risk of developing stroke have poor awareness of their risks, according to one study from a primary healthcare setting in Oman. ${ }^{6}$ Furthermore, it appears that many other neighbouring countries of the Gulf Cooperation Council (GCC) seem no different, with less than a third of the at-risk patients in these countries being barely familiar with the meaning of stroke. $^{7}$

To the best of the authors' knowledge, there has been only a single abstract of a study on ischaemic stroke patients in Oman that has been published thus far. ${ }^{8}$ No detailed studies have been conducted in Oman on stroke patients and hence, this study will be the first to provide the aforementioned information. This study aimed to describe the features of stroke presented by patients to a stroke centre in a tertiary care hospital in Oman. The findings could aid health system planners in decisions for more efficient resource allocation, including necessary clinical services and development of preventive strategies.

\section{Methods}

This cross-sectional hospital-based study included 193 stroke patients prospectively recruited from the Emergency Department (ED) of Khoula Hospital (KH) from November 2017 to April 2018. KH is one of the main governmental tertiary hospitals with a functioning stroke unit in the capital city of Muscat in Oman. In addition, it is the only tertiary stroke centre under the Ministry of Health with a stroke unit in Muscat. This unit also receives referrals from private and remotely located hospitals.

Patients were included in the study if they had experienced an acute or a sub-acute stroke confirmed by computed tomography (CT) scans and/or magnetic resonance imaging (MRI). They had to have also fulfilled the criteria of the American Heart Association/ American Stroke Association according to which an ischaemic stroke is defined as "an episode of neurological dysfunction caused by focal cerebral, spinal, or retinal infarction", and a haemorrhagic stroke is defined as "rapidly developing clinical signs of neurological dysfunction attributable to a focal collection of blood within the brain parenchyma or ventricular system that is not caused by trauma." In the aforementioned regard, Omani and non-Omani patients aged 18 years or above with a confirmed diagnosis of either intra-cerebral haemorrhage or ischaemic stroke were included in the study. Patients with stroke caused by complications arising from trauma were excluded. Subarachnoid haemorrhage was not included in the analysis as there were no cases encountered during the study period.

Datawas collected from the patients' computerised records as well as from interviews with the patient or a close relative to obtain missing variables in the history. The data on functional assessment obtained by the Neurology Unit upon discharge was gathered from the patient's medical record. The tools used for data collection purposes included standard, pretested forms extracting information regarding demographic characteristics, type of acute stroke, ischaemic stroke subtypes, severity, risk factors, acute management, medical comorbidities, duration of hospital admission, functional assessment and outcomes.

Information regarding the following parameters were evaluated as part of the risk factors for stroke (based on previous or current diagnosis): 1) hypertension, defined as systolic pressure $\geq 130$ $\mathrm{mmHg}$ or diastolic pressure $\geq 80 \mathrm{mmHg}$ or the use of antihypertensive medication; 2) diabetes mellitus (DM), defined as use of insulin or an oral hypoglycaemic agent or a fasting glucose value $\geq 126$ $\mathrm{mg} / \mathrm{dL}$; 3) dyslipidaemia, defined as elevated total or low-density lipoprotein cholesterol levels or low levels of high-density lipoprotein cholesterol; and 4) cardiac diseases (atrial fibrillation [AF] and myocardial infarction). Additionally, information regarding a history of current or past tobacco and alcohol use was also obtained. Furthermore, a history of previous stroke and transient ischaemic attacks was also considered.

Ischaemic stroke subtypes were defined according to the Trial of Org 10172 in Acute Stroke Treatment (TOAST) criteria. ${ }^{10}$ This is a widely-used classification with good reliability and high sensitivity and specificity, based on its aetiology of large-artery atherosclerosis (LAA), small-vessel disease or lacunar stroke, cardioembolic stroke, stroke of other defined aetiologies (OD) or stroke of other undetermined aetiology.

The severity of cases was assessed using the National Institutes of Health Stroke Scale (NIHSS). ${ }^{11}$ The total neurological impairment score was interpreted as being very severe (>25), severe (15-24), moderately severe $(5-14)$ or mild $(<5)$. The Glasgow Coma Scale, in which cases are categorised as being mild $(>12)$, moderate $(8-12)$ and severe $(<8)$, was also used. ${ }^{12}$ Functional assessment was assessed using the Modified Rankin Scale (MRS). ${ }^{13}$ The time taken for care provision at each stage of stroke management at the ED including triaging, doctor's evaluation, imaging and time when management began were also recorded to evaluate and account for time delay as a potential reason for non-thrombolysis. 
Table 1: Characteristics of stroke patients presenting to the National Stroke Center in Muscat, Oman ( $=193$ )

\begin{tabular}{|c|c|c|c|}
\hline \multirow[t]{2}{*}{ Characteristics } & \multicolumn{2}{|c|}{ n (\%) } & \multirow{2}{*}{$\begin{array}{c}P \\
\text { value }\end{array}$} \\
\hline & HS & IS & \\
\hline Total & $33(17.1)$ & $160(82.9)$ & \\
\hline Age & & & 0.016 \\
\hline $\begin{array}{l}\text { Age range in } \\
\text { years }\end{array}$ & $27-100$ & $27-96$ & \\
\hline Mean Age \pm SD & $55.79 \pm 16.73$ & $62.13 \pm 12.93$ & \\
\hline Nationality & & & 0.14 \\
\hline Omani & $24(72.7)$ & $134(83.8)$ & \\
\hline Non-Omani & $9(27.3)$ & $26(16.3)$ & \\
\hline Gender & & & 0.25 \\
\hline Male & $16(48.5)$ & $96(60.0)$ & \\
\hline Female & $17(51.5)$ & $64(40.0)$ & \\
\hline Educational status & & & 0.752 \\
\hline Illiterate & $9(27.3)$ & 38 (23.8) & \\
\hline Read/write & $7(21.2)$ & $40(25.0)$ & \\
\hline $\begin{array}{l}\text { Elementary } \\
\text { education }\end{array}$ & $5(15.2)$ & 27 (16.9) & \\
\hline $\begin{array}{l}\text { Secondary } \\
\text { education }\end{array}$ & $6(18.2)$ & $38(23.8)$ & \\
\hline $\begin{array}{l}\text { Higher } \\
\text { education }\end{array}$ & $6(18.2)$ & 17 (10.6) & \\
\hline Marital status & & & 0.934 \\
\hline Single & $2(6.1)$ & $7(4.4)$ & \\
\hline Married & $24(72.7)$ & $121(75.6)$ & \\
\hline Divorced & $1(3.0)$ & $7(4.4)$ & \\
\hline Widowed & $6(18.2)$ & $25(15.6)$ & \\
\hline \multicolumn{2}{|c|}{ Smoking status (current) } & & 0.99 \\
\hline Yes & $2(6.1)$ & $13(8.1)$ & \\
\hline No & 31 (93.9) & $147(91.2)$ & \\
\hline \multicolumn{2}{|c|}{ Alcohol consumption (current) } & & 0.69 \\
\hline Yes & $1(3.0)$ & $11(6.9)$ & \\
\hline No & $32(97.0)$ & $149(93.1)$ & \\
\hline
\end{tabular}

All the data were analysed using the Statistical Package for Social Science (SPSS), Version 20 (IBM Corp., Chicago, Illinois, USA). Statistical inferences were drawn based on two-tailed tests and a $P$ value $<0.05$ was considered statistically significant. For descriptive analysis, the means, medians, standard deviations and 95\% confidence intervals were calculated. The prevalence and frequencies were expressed in terms of percentages and the appropriate tables were designed
Table 2: Stroke-related risk factors of stroke patients presenting to the National Stroke Center in Muscat, Oman $(\mathrm{N}=193)$

\begin{tabular}{|c|c|c|c|}
\hline \multirow[t]{2}{*}{ Variable } & \multicolumn{2}{|c|}{ n (\%) } & \multirow{2}{*}{$\begin{array}{c}P \\
\text { value }\end{array}$} \\
\hline & HS & IS & \\
\hline Total & 33 (17.1) & $160(82.9)$ & \\
\hline Hypertension & $21(63.6)$ & $119(74.4)$ & 0.21 \\
\hline Diabetes mellitus & 13 (39.4) & $92(57.5)$ & 0.06 \\
\hline Dyslipidaemia & $7(21.2)$ & $51(31.9)$ & 0.29 \\
\hline $\begin{array}{l}\text { Ischemic heart } \\
\text { disease }\end{array}$ & $3(9.1)$ & $34(21.3)$ & 0.16 \\
\hline Atrial fibrillation & $4(12.1)$ & $11(6.9)$ & 0.30 \\
\hline $\begin{array}{l}\text { Hypertension } \\
+ \text { diabetes + } \\
\text { dyslipidaemia }\end{array}$ & $6(18.2)$ & $39(24.4)$ & 0.44 \\
\hline $\begin{array}{l}\text { Past history of } \\
\text { stroke }\end{array}$ & $4(12.1)$ & $27(16.9)$ & 0.40 \\
\hline $\begin{array}{l}\text { Family history of } \\
\text { stroke }\end{array}$ & $1(3.0)$ & $3(1.9)$ & 0.53 \\
\hline
\end{tabular}

to describe the study population. Further analysis of ischaemic stroke cases $(n=160)$ was also performed.

The study was approved by the ethics and research committee under the administration unit of the Directorate General of Muscat. Informed consent was obtained from each participant or his/her relative before any interview or neurologic examination was conducted.

\section{Results}

A total of 193 confirmed cases of stroke with a mean age of $61.05 \pm 13.81$ years were included in this study. The majority of cases were categorised as ischaemic strokes $(\mathrm{n}=160,82.90 \%)$ and predominantly male (58\%) among both Omanis and non-Omanis, with a male-female ratio of $1.38: 1$. There was no significant difference between the types of strokes in terms of gender distribution $(P=0.25)$ [Table 1]. More than half (63\%) of the total cases were below 65 years of age with haemorrhagic stroke found mostly among the younger patients. Eight out of 10 stroke patients were Omanis, which could be reflective of the free medical care offered to Omani nationals compared to non-Omanis.

Hypertension was the most prevalent risk factor (72.5\%) followed by DM (54.4\%), which was more common among ischaemic stroke cases. Approximately a quarter of the ischaemic stroke patients reported hypertension, diabetes and dyslipidaemia and 51.3\% of them were in the 40-60-year age group. Among the ischaemic stroke cases, $16.9 \%(n=27)$ and $6.9 \%$ 
Table 3: Severity of stroke and various other stroke-related outcomes of stroke patients presenting to the National Stroke Center in Muscat, Oman $(\mathrm{N}=193)$

\begin{tabular}{|c|c|c|c|}
\hline \multirow[t]{2}{*}{ Variable } & \multicolumn{2}{|c|}{ n (\%) } & \multirow{2}{*}{$\begin{array}{c}P \\
\text { value }\end{array}$} \\
\hline & HS & IS & \\
\hline Total & $33(17.1)$ & $160(82.9)$ & \\
\hline \multicolumn{3}{|c|}{ National Institute of Health Scale Score } & 0.005 \\
\hline Mild & $13(39.4)$ & $109(68.1)$ & \\
\hline Moderate & $11(33.3)$ & $38(23.8)$ & \\
\hline Severe/very severe & $9(27.3)$ & $13(8.1)$ & \\
\hline \multicolumn{3}{|l|}{ Glasgow coma scale } & 0.001 \\
\hline Mild & $23(69.7)$ & $150(93.8)$ & \\
\hline Moderate & $4(12.1)$ & $7(4.4)$ & \\
\hline Severe & $6(18.2)$ & $3(1.9)$ & \\
\hline Complications* & $9(28.1)$ & $22(14.2)$ & 0.07 \\
\hline $\begin{array}{l}\text { Intensive care unit } \\
\text { admission" }\end{array}$ & $16(50.0)$ & $35(22.6)$ & 0.004 \\
\hline Hospital stay $\pm \mathrm{SD}$ & $\begin{array}{l}10.58 \pm \\
11.89\end{array}$ & $\begin{array}{l}7.94 \pm \\
7.31\end{array}$ & 0.09 \\
\hline \multicolumn{3}{|l|}{ Outcome } & 0.35 \\
\hline Died & $5(15.2)$ & $11(6.9)$ & \\
\hline Survived & $27(81.8)$ & 144 (90.0) & \\
\hline Signed LAMA & $1(3.0)$ & $5(3.1)$ & \\
\hline \multicolumn{3}{|c|}{ Modified ranking score upon discharge* } & 0.26 \\
\hline No symptoms & $1(3.1)$ & $12(7.7)$ & \\
\hline $\begin{array}{l}\text { No significant } \\
\text { disability }\end{array}$ & $3(9.4)$ & 30 (19.4) & \\
\hline Slight disability & $4(12.5)$ & $32(20.6)$ & \\
\hline Moderate disability & $10(31.3)$ & $43(27.7)$ & \\
\hline $\begin{array}{l}\text { Moderately sever } \\
\text { disability }\end{array}$ & $6(18.8)$ & $21(13.5)$ & \\
\hline Severe disability & $3(9.4)$ & $5(3.2)$ & \\
\hline Died & $5(15.6)$ & $12(7.7)$ & \\
\hline
\end{tabular}

HS = haemorrhagic Stroke; IS = ischaemic stroke; $C I=$ confidence interval; $S D=$ standard deviation; $L A M A=$ left against medical advice. *Patients who left against medical advice were excluded and percentages have been calculated based on the total number of remaining patients.

( $\mathrm{n}=11$ ) reported history of previous stroke and transient ischaemic attack, respectively [Table 2]. The distribution of cases according to severity are demonstrated in Table 3.

According to the NIHSS score ranking, haemorrhagic stroke cases were more severe compared to ischaemic stroke cases $(P=0.005)$. The severity of stroke incidents correlated with the age group among the ischaemic stroke cases, with $69.2 \%$ of severe cases presenting among patients aged above 60 years
Table 4: Average time spent during different stages of care provision at the Emergency Department for stroke patients presenting on the day of stroke symptom development to the National Stroke Center in Muscat, Oman $(\mathrm{n}=106)$

$\begin{array}{lc}\text { Variable } & \text { Mean in minutes } \pm \text { S } \\ \text { Time from arrival until triage } & 6.77 \pm 4.5 \\ \begin{array}{l}\text { Time from arrival until doctor } \\ \text { evaluation }\end{array} & 7.58 \pm 0.82 \\ \text { Time from arrival until imaging } & 28.53 \pm 3.08\end{array}$

$S D=$ standard deviation

$(P=0.004)$ but not among the haemorrhagic stroke cases $(P=0.816)$. The age group also correlated with outcomes among the haemorrhagic stroke cases $(P$ $=0.002$ ) with five deaths being reported among the haemorrhagic stroke cases; all of these patients were below 40 years of age and had an NIHSS score ranging from severe to very severe. There was no significant difference between the two genders in relation to the NIHSS score $(P=0.488)$ or outcome $(P=0.319)$.

The average time (in minutes) spent on different steps of providing care in the ED for patients being attended to on the day of symptom presentation ( $\mathrm{n}$ = 106) can be found in Table 4. Among these cases, $25.6 \%$ presented directly to the ED while the rest were escorted by ambulance. Among those escorted by ambulance, $96.9 \%$ were diagnosed with a query stroke.

Around half of the cases $(n=82)$ were classified utilising the TOAST classification system, of which $45 \%$ were diagnosed with large artery atherosclerosis, $40 \%$ with small vessel occlusion, $9 \%$ with stroke of other undetermined aetiology and 6\% were cardioembolic. The rest of the cases, however, did not receive any classification. The majority of the cases that were classified were diagnosed with LAA followed by small vessel occlusion.

Around $53.7 \%$ of the ischaemic stroke cases presented on the day the symptoms of stroke developed. Approximately 5.8\% of early presenting cases had a contraindication for thrombolysis. Only $19(11.9 \%)$ of all ischaemic stroke cases $(n=160)$ had intravenous thrombolysis, five of whom died.

\section{Discussion}

To the best of the authors' knowledge, this is the first detailed account of the characteristics of stroke patients presenting to the main National Stroke Center in Oman. In this study, several aspects related to stroke among patients presenting acutely to a tertiary care hospital were looked at. These included demographics, associated risk factors, clinical presentation and their sequelae. The mean age for stroke in the current 
population was similar to the mean age reported by many South Asian countries. For example, the mean age was 59 years in Pakistan and 63 years in India. ${ }^{14}$ In the Western world, however, the mean age of incident stroke was higher, (68 years in the USA and 71 years in Italy). ${ }^{15}$ This finding may be a source of concern considering the relatively young age of stroke onset for both its types in Oman. However, it is known from experience that the documentation of age in Oman has been inaccurate in the past, especially for generations born prior to the 1970s. During those times, Oman had an underdeveloped system for civil registration of vital statistics, including recording birth dates. Most of the current cohort afflicted by stroke were born at home with no birth certificates. Furthermore, patients from this generation tended to underestimate their age when asked for the same as part of the medical records at admission. Therefore, the average age of incident stroke cases at onset may actually be closer to that of the Western world than it appears now.

Since stroke is potentially preventable through control of its risk factors, it is important to identify these risk factors and determine their relative prevalence in order to manage them through primary prevention. Hypertension can lead to ischaemic stroke through acceleration of the development of atherosclerosis which results in atherothrombotic events. The relationship between hypertension and haemorrhagic stroke is also well documented with global consistency. ${ }^{16}$ Uncontrolled hypertension is the main cause for primary intracerebral haemorrhage. This can be prevented through good blood pressure control and regular medical check-ups to diagnose hypertension early. Patients are often diagnosed with hypertension only after the development of a target organ issue such as a haemorrhagic stroke. ${ }^{17}$

Approximately half of the patient population in the present study had DM with a significantly higher prevalence in the ischaemic stroke group. Ischaemic stroke is known to be independently associated with $\mathrm{DM}$ which increases its risk two to six times. However, with regards to haemorrhagic stroke, the link with diabetes has not been consistent. AF is another risk factor associated with ischaemic stroke. AF is also associated with a higher risk of stroke recurrence, whether it is diagnosed after or known before the stroke incident. ${ }^{18}$ It is interesting to note that the prevalence of AF in the present ischaemic stroke group was approximately $8 \%$, significantly lower than the internationally reported rate which can reach as high as one third of the stroke cases. ${ }^{19}$ Whether this represents a generally lower incidence of AF in the current sample or more efficient management of existing AF with anticoagulation leading to a lower incidence of thrombotic complications remains unclear. However, it is important to note that AF can get picked-up later during the patient's hospital course or later during follow-up with a cardiologist using Holter monitoring; hence, it is possible that some cases were not identified during the patients' course of admission at the ED.

Other risk factors known to have an association with stroke were analysed. These included past history of transient ischaemic attacks, dyslipidaemia, ischaemic heart disease and a family history of stroke. These factors were more commonly absent than present in the current population.

The majority of strokes were of the ischaemic type constituting more than $80 \%$ of cases with the rest being haemorrhagic. This is consistent with reports from Western countries where ischaemic stroke is significantly more common than haemorrhagic stroke. ${ }^{20}$ Studies from other Arab countries, including the GCC, reported variable proportions for ischaemic stroke ranging from approximately $58 \%$ to $87 \%$, with the highest being reported in Saudi Arabia and the lowest in Bahrain and Sudan, where haemorrhagic stroke comprised a larger percentage..$^{21-23}$ The latter is more consistent with the pattern of strokes observed in the Eastern part of the globe, where the incidence of haemorrhagic stroke is reported to be twice that seen in the West. ${ }^{24}$ This higher incidence is even seen in East Asians who have immigrated to the West. ${ }^{25}$ These differences may partly be related to ethnicity, a factor which was not explored in this study. ${ }^{26}$ The fact that the current findings mirror the Western patterns of this disease may be a reflection of the change in lifestyle in Oman that has accompanied the rapid modernisation and development that the country has witnessed over the past four decades, including changes in the healthcare system. Furthermore, the lower rate of haemorrhagic stroke is likely due to implementation of treatment screening programmes for the hypertension, a significant factor known to be related to haemorrhagic strokes. ${ }^{27,28}$

When comparing the severity of the two subtypes of stroke, haemorrhagic stroke had significantly worse outcomes compared to ischaemic stroke with a higher incidence of requiring admission to the intensive care unit and a longer hospital stay. The incidence of death was twice as common in haemorrhagic strokes. This is consistent with findings from many international studies. $^{29}$ Intracranial haemorrhage causes more severe strokes and is known to be an independent predictor of poor neurological outcomes with higher odds of long-term disability. This is a direct result of haemorrhage causing larger anatomic lesions when compared to ischaemia-induced strokes. ${ }^{30}$ The in- 
hospital mortality rate of haemorrhagic stroke was relatively low compared to other reports. ${ }^{31}$

This study has certain strengths and limitations. This is the first study from Oman to prospectively collect data from patients during their ED visits. It systematically reviewed the burden of stroke admitted to the National Stroke Center. The findings from this study can be utilised to inform future research in the country and to guide appropriate preventive strategies as well as resource allocation.

One limitation of this study is that it is a singlecentre study; therefore, the findings may not be considered to be generalisable to the entire population. Furthermore, the sample size was relatively small, which may affect the reliability of the obtained statistical results. Another limitation is that patients were only interviewed during their ED visits, which limited the collection of other variables that may have been relevant and could have been collected if the study had included following the patients' in-hospital course. In addition, patients were not followed-up with throughout their rehabilitation course, limiting the information obtained on their pattern of recovery. For future studies, it will be important to expand the research to include all stroke patients admitted to hospitals in Oman. The adequacy of long-term and rehabilitation facilities for stroke patients is still to be assessed in Oman.

\section{Conclusion}

This study provides essential data on stroke characteristics which is important in developing effective prevention, management and rehabilitation strategies specific to Oman's population. Most of the information obtained conforms with that described internationally and, therefore, similar preventive strategies can be implemented. Furthermore, the information can be utilised by health administrators in planning resource allocation. Further research is needed to explore rehabilitation aspects and long-term outcomes.

\section{CONFLICT OF INTEREST}

The authors declare no conflicts of interest.

\section{FUNDING}

No funding was received for this study.

\section{AUTHORS' CONTRIBUTION}

$\mathrm{HH}, \mathrm{AK}, \mathrm{JL}$ conceptualised and designed the study. LZ, ON, IL, GM, AE AB collected the data. HH, $\mathrm{AK}, \mathrm{JL}$ analysed and interpreted the results. $\mathrm{HH}$, AK, JL drafted the manuscript. All authors reviewed the results and approved the final version of the manuscript.

\section{References}

1. Murray CJ, Vos T, Lozano R, Naghavi M, Flaxman AD, Michaud C, et al. Disability-adjusted life years (DALYs) for 291 diseases and injuries in 21 regions, 1990-2010: A systematic analysis for the Global Burden of Disease Study 2010. The Lancet 2012; 380:2197-223. https://doi.org/10.1016/S0140-6736(12)61689-4.

2. Feigin VL, Forouzanfar MH, Krishnamurthi R, Mensah GA, Connor M, Bennett DA, et al. Global Burden of Diseases, Injuries, and Risk Factors Study 2010 (GBD 2010) and the GBD Stroke Experts Group. Global and regional burden of stroke during 1990-2010: findings from the Global Burden of Disease Study 2010. The Lancet 2014; 383:245-54. https://doi. org/10.1016/s0140-6736(13)61953-4.

3. Benamer HT, Grosset D. Stroke in Arab countries: A systematic literature review. J Neurol Sci 2009; 284:18-23. https://doi. org/10.1016/j.jns.2009.04.029

4. Mokdad AH, Jaber S, Aziz MI, AlBuhairan F, AlGhaith AJ, AlHamad NM, et al. The state of health in the Arab world, 1990-2010: An analysis of the burden of diseases, injuries, and risk factors. The Lancet 2014; 383:309-20. https://doi.org/10.10 16/S0140-6736(13)62189-3.

5. World Health Organization. Global Burden of Diseases. From: https://vizhub.healthdata.org/gbd-compare Accessed: Jun 2019.

6. Al Shafaee MA, Ganguly SS, Al Asmi AR. Perception of stroke and knowledge of potential risk factors among Omani patients at increased risk for stroke. BMC Neurol 2006; 6:38. https://doi. org/10.1186/1471-2377-6-38.

7. Kamran S, Bener AB, Deleu D, Khoja W, Jumma M, Al Shubali A, et al. The level of awareness of stroke risk factors and symptoms in the Gulf Cooperation Council countries: Gulf Cooperation Council stroke awareness study. Neuroepidemiol 2007; 29:235-42. https://doi.org/10.1159/000112856.

8. Gujjar AR, Ramachandiran N, Jacob PC, Al-Azri F, Ganguly SS, Shoaib RH et al. Ischemic stroke outcomes in Oman: Experience of a university-hospital based stroke registry. J Neurol Sci 2015; 357:e380. https://doi.org/10.1016/j.jns.2015.08.1353.

9. Sacco RL, Kasner SE, Broderick JP, Caplan LR, Connors JJ, Culebras A, et al. An updated definition of stroke for the 21st century: A statement for healthcare professionals from the American Heart Association/American Stroke Association. Stroke 2013; 44:2064-89. https://doi.org/10.1161/STR.0b013e318296aeca.

10. Adams Jr HP, Bendixen BH, Kappelle LJ, Biller J, Love BB, Gordon DL, et al. Classification of subtype of acute ischemic stroke. Definitions for use in a multicenter clinical trial. TOAST. Trial of Org 10172 in acute stroke treatment. Stroke 1993; 24:35-41. https://doi.org/10.1161/01.str.24.1.35.

11. Brott T, Adams HP, Olinger CP, Marler JR, Barsan WG, Biller J, et al. Measurements of acute cerebral infarction: A clinical examination scale. Stroke 1989;20:864-70.https://doi.org/110.1161/0 1.str.20.7.864.

12. Teasdale G, Jennett B. Assessment of coma and impaired consciousness: A practical scale. The Lancet 1974; 304:81-4. https://doi.org/10.1016/s0140-6736(74)91639-0.

13. Rankin J. Cerebral vascular accidents in patients over the age of 60: II. Prognosis. Scott Med J 1957; 2:200-15. https://doi.org/1 $0.1177 / 003693305700200504$

14. Wasay M, Khatri IA, Kaul S. Stroke in South Asian countries. Nat Rev Neurol 2014; 10:135-43. https://doi.org/10.1038/ nrneurol.2014.13.

15. GrysiewiczRA, ThomasK, PandeyDK.Epidemiologyofischemic and hemorrhagic stroke: Incidence, prevalence, mortality, and risk factors. Neurol Clin 2008; 26:87195. https://doi.org/10.10 16/j.ncl.2008.07.003. 
16. Woo D, Haverbusch M, Sekar P, Kissela B, Khoury J, Schneider A, Kleindorfer D, et al. Effect of untreated hypertension on hemorrhagic stroke. Stroke 2004; 35:1703-8. https://doi.org/10.1161/01. STR.0000130855.70683.c8.

17. Zia E, Hedblad B, Pessah-Rasmussen H, Berglund G, Janzon L, Engström G. Blood pressure in relation to the incidence of cerebral infarction and intracerebral hemorrhage. Hypertensive hemorrhage: Debated nomenclature is still relevant. Stroke 2007; 38:2681-85. https://doi.org/10.1161/STROKEAHA.106.479725.

18. Yang XM, Rao ZZ, Gu HQ, Zhao XQ, Wang CJ, Liu LP, et al. Atrial fibrillation known before or detected after stroke share similar risk of ischemic stroke recurrence and death. Stroke 2019; 50:1124-9. https://doi.org/10.1161/STROKEAHA.118.024176.

19. Otite FO, Khandelwal P, Chaturvedi S, Romano JG, Sacco RL, Malik AM. Increasing atrial fibrillation prevalence in acute ischemic stroke and TIA. Neurol 2016; 87:2034-42. https://doi. org/10.1212/WNL.0000000000003321.

20. Koton S, Schneider AL, Rosamond WD, Shahar E, Sang Y, Gottesman RF, et al. Stroke incidence and mortality trends in US communities, 1987 to 2011. JAMA 2014; 312:259-68. https://doi.org/10.1001/jama.2014.7692.

21. Yaqub BA, Shamena AR, Kolawole TM, Patel PJ.Cerebrovascular disease in Saudi Arabia. Stroke 1991; 22:1173-6. https://doi. org/10.1161/01.str.22.9.1173.

22. Sokrab TE, Sid-Ahmed FM, Idris MN. Acute stroke type, risk factors, and early outcome in a developing country: A view from Sudan using a hospital-based sample. J Stroke Cerebrovasc Dis 2002; 11:63-5. https://doi.org/10.1053/jscd.2002.126690.

23. Al-Jishi AA, Mohan PK. Profile of stroke in Bahrain. Neurosci 2000; 5:30-4
24. Suzuki K, Izumi M. The incidence of hemorrhagic stroke in Japan is twice compared with Western countries: The Akita stroke registry. Neurol Sci 2015; 36:155-60. https://doi.org/10.1007/ s10072-014-1917-z.

25. Khan FA, Zia E, Janzon L, Engstrom G. Incidence of stroke and stroke subtypes in Malmo, Sweden, 1990-2000: Marked differences between groups defined by birth country. Stroke 2004; 35:2054-8. https://doi.org/10.1161/01.STR.0000135761.18954.0b.

26. Sacco RL, Boden-Albala B, Abel G, Lin IF, Elkind M, Hauser WA, et al. Race-ethnic disparities in the impact of stroke risk factors: The northern Manhattan stroke study. Stroke 2001; 32:1725-31. https://doi.org/10.1161/01.str.32.8.1725.

27. Liu XF, van Melle G, Bogousslavsky J. Analysis of risk factors in 3901 patients with stroke. Chin Med Sci 2005; 20:35-9.

28. Song Y-M, Sung J, Lawlor D, Smith GD, Shin Y, Ebrahim S. Blood pressure, haemorrhagic stroke, and ischemic stroke: The Korean national prospective occupational cohort study. BMJ 2004; 328:324-5. https://doi.org/10.1136/bmj.328.7435.324.

29. Andersen KK, Olsen TS, Dehlendorff C, Kammersgaard LP. Hemorrhagic and ischemic strokes compared: stroke severity, mortality, and risk factors. Stroke 2009; 40:2068-72. https://doi. org/10.1161/STROKEAHA.108.540112.

30. Chiu D, Peterson L, Elkind MS, Rosand J, Gerber LM, Silverstein MD. Comparison of outcomes after intracerebral hemorrhage and ischemic stroke. J Stroke Cerebrovasc Dis 2010; 19:225-9. https://doi.org/10.1016/j.jstrokecerebrovasdis.2009.06.002.

31. González-Pérez A, Gaist D, Wallander MA, McFeat G, GarcíaRodríguez LA. Mortality after hemorrhagic stroke: Data from general practice (The Health Improvement Network). Neurol 2013;81:559-65. https://doi.org/10.1212/WNL.0b013e31829e6eff. 